\title{
Research on Supply Chain Stability Driven by Consumer's Channel Preference Based on Complexity Theory
}

\author{
Yi Tian, Junhai Ma $(\mathbb{D}$, and Wandong Lou $(\mathbb{D})$ \\ College of Management and Economics, Tianjin University, Tianjin 300072, China \\ Correspondence should be addressed to Junhai Ma; mjhtju@aliyun.com and Wandong Lou; wd1160211@126.com
}

Received 22 January 2018; Accepted 3 May 2018; Published 7 August 2018

Academic Editor: Borja Sanz-Altamira

Copyright (C) 2018 Yi Tian et al. This is an open access article distributed under the Creative Commons Attribution License, which permits unrestricted use, distribution, and reproduction in any medium, provided the original work is properly cited.

\begin{abstract}
At present, most of the manufacturers are increasingly laying emphasis on dual-channel selling. The level of consumer's preference is diverse with different channels. This study discusses a supply chain where one common manufacturer uses two different channels to sell product. The bounded rationality expectation has been applied to explore the decision-making mechanism in finalizing the wholesale prices and sales commissions for the manufacturer and retailers. In addition, the dynamic features of the system are simulated by 2D bifurcation diagram, the largest Lyapunov exponent, attractor variation, and time series. The simulation results suggest that if the adjustment speeds of the wholesale prices and sales commissions change drastically, the system would fall into a chaotic state. If the consumers prefer the online channel, the wholesale prices and sales commissions may be raised and vice versa. However, too strong preference of each channel will make the system appear to have a considerably periodic fluctuation, even chaos. In the meantime, the parameter adjustment method can help make the periodic or chaotic system go back to stability. Therefore, the significance of this study is with a practical meaning to make better pricing strategy for players in dual-channel selling supply chain system.
\end{abstract}

\section{Introduction}

The rapid development of Internet technology and social economy promoted a huge amount of manufacturers who had been transferred from traditional retailing to the combination of traditional and electronic retailing. For instance, according to the data provided by the China Academy of Information and Communications Technology (CAICT), sales of smart phone in China records nearly 390 million at year-end of 2016. Huawei took a 16.4 percent market share in China, while Apple, 9.6 percent. Smart phone manufacturers always distribute their products through both traditional and online channels. In this research, a pricing problem in supply chain with one manufacturer (Huawei) who supplies an identical product (Mate 9) to two retailers (China Resources Vanguard Co. Ltd. and JD.com) is brought to discussion. CR Vanguard is one of the world's top five hundred enterprises, and it is China's largest supermarket chains by a number of stores for years. JD.com is a typical Chinese e-commerce company which is one of the biggest e-malls in China with self-support storage and logistics system. CR Vanguard and JD.com are the typical representatives of traditional and online channels for smartphone sales, respectively. Different consumers will choose their own preferred buying channels. Therefore, the supply chain driven by the consumer's channel preference is necessary to be studied.

Two-echelon supply chain has been widely paid attention to and discussed in academia. Ma, Ma and Bao $[1,2]$ investigated the bullwhip effect in a two-echelon supply chain. This study discusses a supply chain which consists of one common manufacturer and two retailers from traditional and online sales channels, respectively. The manufacturer determines the wholesale prices and the two retailers decide their own sales prices.

In the current studies [3-7], the consumer preference is frequently considered as one of the chief factors that influence the marketing. Especially, consumer's channel preference is a hot topic in supply chain research. Khouja et al. [8] analyzed the manufacturer's channel selection and pricing problem. They considered consumer's preferences under different distribution strategies. Gao and $\mathrm{Su}$ [9] 
investigated a stylized model where a retailer operated the dual-channel. Customers strategically make channel choices that included both online and offline. Ke and Liu [10] discussed a dual-channel supply chain competition with channel preference under an uncertain environment. Their results indicated that the customer's direct-channel preference had the opposite effect on the profit of supplier and retailer. Gan et al. [11] presented pricing decisions and profits of supply chain members in a closed-loop supply chain and considered the parameter of customer's direct channel preference as a key factor.

Different from the above mentioned literatures, this paper discusses the decision-making of wholesale prices and sales commissions for manufacturer and retailers based on the bounded rationality expectation by employing complexity theory to explore the effect of the adjustment speed of the above variables on the system stability. More and more researchers used bounded rational theory to analyze the economic model. Ma and Wang [12] applied two noncooperative game models to study the bounded rationality expectation. Song and Zhao [13] pointed out a decisionmaking problem of newsvendor system with strategic customers of bounded rationality. Ma and $\mathrm{Si}$ [14] established a continuous Bertrand duopoly game model with twostage delay to investigate the influence of delay and weight on the complex dynamic characteristics of the system. Ma and Xie [15] analyzed the comparison and complexity on a dual-channel supply chain under the different channel power structures and uncertain demand. Ma and Xie [16] discussed the impact of loss sensitivity on a mobile phone supply chain system stability based on the chaos theory. In conclusion, it has received a considerable amount of attention to apply bounded rationality and complexity theory to study the management problems in the supply chain.

In reality, the exploration of the supply chain driven by consumer's channel preference based on chaos theory has a great significance. In this paper, besides the adjusted basic parameters such as the wholesale prices and sales commissions, the consumer's channel preference is also discussed. The results indicated that the preference plays an important role in status transformation from stability to chaos. In this analysis, a supply chain model which depicts one common manufacturer using two different channels to sell its product is built in the first place. Then, the bounded rationality expectation is applied to study the complex dynamics of the system. Furthermore, the dynamic characteristics of the system are discussed by $2 \mathrm{D}$ bifurcation diagram, the largest Lyapunov exponent, attractor variation, and time series. The results indicate that not only the drastic adjustment of traditional parameters such as the wholesale prices and sales commissions can make the system go chaotic but also the consumer's channel preference can also lead to system considerably periodic fluctuation, even to chaos, which is the primary finding in this article. Finally, the parameter adjustment control method is performed on the system to return the periodic or the chaotic state to stability. The conclusions of this paper can give constructive suggestions for managers of both manufacturers and retailers.
The structure of this paper is as follows. In Section 2, the basic model considering the influence of consumer's channel preference is established. In this part, the optimal decision of the complex dynamic system is analyzed. Following Section 2 , this study further applies numerical simulation to investigate the stability aspect and the dynamical behaviors. 2D bifurcation diagram, the largest Lyapunov exponent, attractor, and time series have been utilized to study the influence on the supply chain. In Section 4, we introduce the method to control the chaos system. Finally, the conclusion of this research is provided.

\section{Demand Model}

A supply chain system consists of one manufacturer and two retailers, one of which is a traditional retailer (retailer 1 ) and the other is an online retailer (retailer 2), which has been restricted in this study. The manufacturer provides an identical product at a constant unit cost $(c)$ and wholesale prices $\left(w_{i}\right)$ to retailer 1 and retailer 2 . Then, the retailers distribute the product to consumers in a common market by traditional and online channels, respectively. The retailers decide their unit sales commissions $k_{i}, i=1,2$. Retailer 1 and retailer 2 have a competitive relationship between each other as shown in Figure 1.

Hence, the sales prices of this supply chain can be described as $p_{i}=w_{i}+k_{i}, i=1,2$. The demand function is simplified as the following linear form:

$$
q_{i}=d_{i}-(\delta+\gamma) p_{i}+\gamma p_{3-i}, \quad i=1,2 .
$$

This simplified linear demand function has been used by Anderson and Bao [17], Wu et al. [18], Yang and Zhou [19], and Choi [20]. Here, $d_{i}$ is the market base of channel $i, p_{i}$ is the sales price of retailer $i, \delta$ is the price sensitivity of the product, and $\gamma$ denotes the substitutability of the retailers. In order to discuss the influence of consumer's channel preference and pricing strategies on the performance of the supply chain members without loss of generality, the method proposed by Mcguire and Staelin [21] has been applied to rescale the demand functions in (1). The scaled model can conduct some analytical comparisons instead of numerical experiments reported in Xiao et al. [22]. Let $\mu=\gamma /(\gamma+\delta)$; the above linear function will be changed as

$$
q_{i}^{\prime}=d_{i}^{\prime}-\frac{\delta}{(1-\mu)} p_{i}^{\prime}+\frac{\delta \mu}{(1-\mu)} p_{3-i}^{\prime}, \quad i=1,2 .
$$

The substitutability of the two retailers in terms of changes in prices has been denoted as parameter $\mu$. Let $\phi_{1}=d_{1}^{\prime}-\delta c^{\prime}$ $\equiv \phi, \phi_{2}=d_{2}^{\prime}-\delta c^{\prime}$ and $d_{1}^{\prime} \leq d_{2}^{\prime}$, and define $\eta=\left(d_{2}^{\prime}-\delta c^{\prime}\right) /$ $\left(d_{1}^{\prime}-\delta c^{\prime}\right)$. The parameter $\eta(\eta \geq 1)$ depicts the consumer's channel preference.

$\mu=0$ represents the scenario in which the submarket is monopolized by one retailer. $\mu=1$ represents the scenario in which there exist two completely substitutable retailers. Then, the prices can be standardized as $k_{i}=(\delta /(\phi(1-\mu))) k_{i}^{\prime}, w_{i}=$ $(\delta /(\phi(1-\mu)))\left(w_{i}^{\prime}-c^{\prime}\right)$, and $p_{i}=(\delta /(\phi(1-\mu)))\left(w_{i}^{\prime}+k_{i}^{\prime}-c^{\prime}\right)$. 


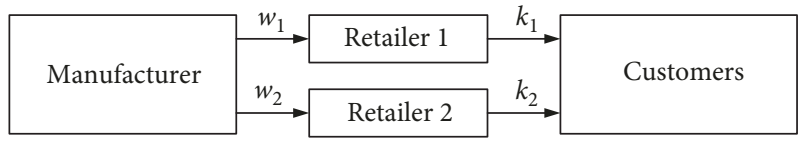

Figure 1: The model of supply chain.

The demand function $q_{1}^{\prime}$ can be formulated as follows:

$$
q_{1}^{\prime}=d_{1}^{\prime}-\frac{\delta}{(1-\mu)} p_{1}^{\prime}+\frac{\delta}{(1-\mu)} p=\phi\left(1-p_{1}+\mu p_{2}\right) .
$$

$q_{2}^{\prime}$ can be obtained by using the same method:

$$
q_{2}^{\prime}=d_{2}^{\prime}-\frac{\delta}{(1-\mu)} p_{2}^{\prime}+\frac{\delta \mu}{(1-\mu)} p_{1}^{\prime}=\phi\left(\eta-p_{2}+\mu p_{1}\right) .
$$

So we can get the demands as below:

$$
q_{1}=\frac{q_{1}^{\prime}}{\phi}=1-p_{1}+\mu p_{2}, \quad q_{2}=\frac{q_{2}^{\prime}}{\phi}=\eta-p_{2}+\mu p_{1} .
$$

But in reality, the market requirements are often influenced by some other factors; here, $\varepsilon_{i}$ is used to represent these disturbance factors in research.

$$
\begin{aligned}
& q_{1}=\frac{q_{1}^{\prime}}{\phi}=1-p_{1}+\mu p_{2}+\varepsilon_{1}, \\
& q_{2}=\frac{q_{2}^{\prime}}{\phi}=\eta-p_{2}+\mu p_{1}+\varepsilon_{2} .
\end{aligned}
$$

$\varepsilon_{i}(i=1,2)$ follows a normal distribution such that $E\left(\varepsilon_{i}\right)$ $=0$, $\operatorname{var}\left(\varepsilon_{i}\right)=\sigma^{2}$. The expected profit decision models of the manufacturer and two retailers are shown as

$$
\begin{aligned}
E\left(\pi_{r 1}\right)= & k_{1}\left(1-\left(k_{1}+w_{1}\right)+\mu\left(k_{2}+w_{2}\right)\right), \\
E\left(\pi_{r 2}\right)= & k_{2}\left(\eta-\left(k_{2}+w_{2}\right)+\mu\left(k_{1}+w_{1}\right)\right), \\
E\left(\pi_{m}\right)= & w_{1}\left(1-\left(k_{1}+w_{1}\right)+\mu\left(k_{2}+w_{2}\right)\right) \\
& +w_{1}\left(\eta-\left(k_{2}+w_{2}\right)+\mu\left(k_{1}+w_{1}\right)\right) .
\end{aligned}
$$

In order to deduce the marginal profits of the manufacturer and two retailers, the first-order partial derivative of (7) can be calculated as follows:

$$
\begin{aligned}
& \frac{\partial E\left(\pi_{r 1}\right)}{\partial k_{1}}=1-2 k_{1}-w_{1}+\left(k_{2}+w_{2}\right) \mu, \\
& \frac{\partial E\left(\pi_{r 2}\right)}{\partial k_{2}}=-2 k_{2}-w_{2}+\eta+\left(k_{1}+w_{1}\right) \mu, \\
& \frac{\partial E\left(\pi_{m}\right)}{\partial w_{1}}=1-k_{1}-2 w_{1}+w_{2} \mu+\left(k_{2}+w_{2}\right) \mu, \\
& \frac{\partial E\left(\pi_{m}\right)}{\partial w_{2}}=-k_{2}-2 w_{2}+\eta+w_{1} \mu+\left(k_{1}+w_{1}\right) \mu .
\end{aligned}
$$

2.1. Optimal Decision. In the market, the optimal decisions of the retailers and manufacturer are influenced by each other. Therefore, this study assumes that they share overlapping information. In this research, when the marginal profits reduce to zero, the optimal decision for retailers and manufacturer can be obtained. The wholesale prices and sales commissions are the decision variables. The research calculates the firstorder derivative of the retailers' and manufacturer's profit. When the marginal profit equals to zero, the optimal wholesale prices and sales commissions can be derived. The detailed process is as follows:

$$
\begin{aligned}
& \frac{\partial E\left(\pi_{r 1}\right)}{\partial k_{1}}=0, \\
& \frac{\partial E\left(\pi_{r 1}\right)}{\partial k_{2}}=0, \\
& \frac{\partial E\left(\pi_{m}\right)}{\partial w_{1}}=0, \\
& \frac{\partial E\left(\pi_{m}\right)}{\partial w_{2}}=0 .
\end{aligned}
$$

The optimal solution of the system will be solved.

$$
\begin{aligned}
& k_{1}^{*}=-\frac{3+\eta \mu}{-9+\mu^{2}}, \\
& k_{2}^{*}=-\frac{3 \eta+\mu}{-9+\mu^{2}}, \\
& w_{1}^{*}=-\frac{-3-4 \eta \mu-\mu^{2}}{\left(-9+\mu^{2}\right)\left(-1+\mu^{2}\right)}, \\
& w_{2}^{*}=-\frac{-3 \eta-4 \mu-\eta \mu^{2}}{\left(-9+\mu^{2}\right)\left(-1+\mu^{2}\right)} .
\end{aligned}
$$

2.2. The Complex Dynamics of the System. The real market is a changeable and complex system. The manufacturer and retailers cannot know the complete market information, and predict other decision-makers' information accurately. Hence, the bounded rationality expectations have been universally adopted by market decision-makers. The decision of $t+1$ period is as follows:

$$
\begin{aligned}
& k_{1}(t+1)=k_{1}(t)+g_{1} k_{1}(t) \frac{\partial E\left(\pi_{r 1}(t)\right)}{\partial k_{1}(t)}, \\
& k_{2}(t+1)=k_{2}(t)+g_{2} k_{2}(t) \frac{\partial E\left(\pi_{r 2}(t)\right)}{\partial k_{2}(t)}, \\
& w_{1}(t+1)=w_{1}(t)+g_{3} w_{1}(t) \frac{\partial E\left(\pi_{m}(t)\right)}{\partial w_{1}(t)}, \\
& w_{2}(t+1)=w_{2}(t)+g_{4} w_{2}(t) \frac{\partial E\left(\pi_{m}(t)\right)}{\partial w_{2}(t)} .
\end{aligned}
$$

In the paper, the price adjustment speeds consist of two wholesale prices and sales commissions. Here, $g_{i}>0(i=1,2$, $3,4) ; g_{1}$ and $g_{2}$ are the adjustment speed of the sales commissions with retailer 1 and retailer 2 , respectively. $g_{3}$ and $g_{4}$ represent the adjustment speed of the wholesale prices with the manufacturer. Based on the above equation, the fourdimensional discrete dynamic system can be acquired and expressed in (12). The wholesale prices and the sales commissions in the next period depend on the estimation of these 
period marginal profits. Base on that, the adjustment of bounded rationality is completed. If the entity's current marginal profit is positive, the price will increase during the next period for higher profits. If the entity's current marginal profit is negative, the price should be reduced during the next period. The dynamic adjustment processes are as follows:

$$
\begin{aligned}
& k_{1}(t+1)=k_{1}(t)+g_{1} k_{1}(t)\left(1-2 k_{1}-w_{1}+\left(k_{2}+w_{2}\right) \mu\right), \\
& k_{2}(t+1)=k_{2}(t)+g_{2} k_{2}(t)\left(-2 k_{2}-w_{2}+\eta+\left(k_{1}+w_{1}\right) \mu\right), \\
& w_{1}(t+1)=w_{1}(t)+g_{3} w_{1}(t)\left(1-k_{1}-2 w_{1}+w_{2} \mu+\left(k_{2}+w_{2}\right) \mu\right), \\
& w_{2}(t+1)=w_{2}(t)+g_{4} w_{2}(t)\left(-k_{2}-2 w_{2}+\eta+w_{1} \mu+\left(k_{1}+w_{1}\right) \mu\right) .
\end{aligned}
$$

After a long period of operation, when $k_{i}(t+1)=k_{i}(t)$ and $w_{i}(t+1)=w_{i}(t)$, the system will become steady. Under the equilibrium state, all parties in the game cannot increase profits for themselves by changing the decision variables. Therefore, when the decision variables take the values of the equilibrium state, every player in the game can obtain the maximized profit. There are sixteen equilibriums of system (12):

$$
\begin{aligned}
& E_{1}(0,0,0,0) \text {, } \\
& E_{2}\left(0,0,0, \frac{\eta}{2}\right) \text {, } \\
& E_{3}\left(0,0,-\frac{1+\eta \mu}{2\left(-1+\mu^{2}\right)},-\frac{\eta+\mu}{2\left(-1+\mu^{2}\right)}\right) \text {, } \\
& E_{4}\left(0,0, \frac{1}{2}, 0\right) \text {, } \\
& E_{5}\left(0, \frac{\eta}{3},-\frac{1+\eta \mu}{2\left(-1+\mu^{2}\right)},-\frac{2 \eta+3 \theta+\eta \mu^{2}}{6\left(-1+\mu^{2}\right)}\right) \text {, } \\
& E_{6}\left(0, \frac{\eta}{3}, 0, \frac{\eta}{3}\right) \text {, } \\
& E_{7}\left(0, \frac{\eta}{2}, 0,0\right) \text {, } \\
& E_{8}\left(0,-\frac{2 \eta+\mu}{-4+\mu^{2}},-\frac{2+\eta \mu}{-4+\mu^{2}}, 0\right) \text {, } \\
& E_{9}^{*}\left(-\frac{3+\eta \mu}{-9+\mu^{2}},-\frac{3 \eta+\mu}{-9+\mu^{2}},-\frac{-3-4 \eta \mu-\mu^{2}}{\left(-9+\mu^{2}\right)\left(-1+\mu^{2}\right)},\right. \\
& \left.-\frac{-3 \eta-4 \mu-\eta \mu^{2}}{\left(-9+\mu^{2}\right)\left(-1+\mu^{2}\right)}\right) \\
& E_{10}\left(\frac{1}{3}, 0,-\frac{2+3 \eta \mu+\mu^{2}}{6\left(-1+\mu^{2}\right)},-\frac{\eta+\mu}{2\left(-1+\mu^{2}\right)}\right) \text {, } \\
& E_{11}\left(-\frac{2+\eta \mu}{-4+\mu^{2}}, 0,0,-\frac{2 \eta+\mu}{-4+\mu^{2}}\right) \text {, } \\
& E_{12}\left(\frac{1}{2}, 0,0,0\right) \\
& E_{13}\left(\frac{1}{3}, 0, \frac{1}{3}, 0\right),
\end{aligned}
$$

$$
\begin{aligned}
& E_{14}\left(-\frac{3+2 \eta \mu}{2\left(-3+\mu^{2}\right)},-\frac{2 \eta+\mu}{2\left(-3+\mu^{2}\right)}, 0,-\frac{2 \eta+\mu}{2\left(-3+\mu^{2}\right)}\right), \\
& E_{15}\left(-\frac{2+\eta \mu}{-4+\mu^{2}},-\frac{2 \eta+\mu}{-4+\mu^{2}}, 0,0\right), \\
& E_{16}\left(-\frac{2+\eta \mu}{2\left(-3+\mu^{2}\right)},-\frac{3 \eta+2 \mu}{2\left(-3+\mu^{2}\right)},-\frac{2+\eta \mu}{2\left(-3+\mu^{2}\right)}, 0\right) .
\end{aligned}
$$

For these above equilibriums, it can be found that $E_{9}^{*}$ is the only point which is completely nonzero. The others are boundary points. $E_{9}^{*}$ is the unique Nash equilibrium point. The Jacobian matrix of system (12) can be calculated as follows:

$\mathbf{J}(E)=\left(\begin{array}{cccc}1-2 g_{1} k_{1} & g_{1} k_{1} \mu & -g_{1} k_{1} & g_{1} k_{1} \mu \\ g_{2} k_{2} \mu & 1-2 g_{2} k_{2} & g_{2} k_{2} \mu & -g_{2} k_{2} \\ -g_{3} w_{1} & g_{3} w_{1} \mu & 1-2 g_{3} w_{1} & 2 g_{3} w_{1} \mu \\ g_{4} w_{2} \mu & -g_{4} w_{2} & 2 g_{4} w_{2} \mu & 1-2 g_{4} w_{2}\end{array}\right)$

The Jacobian matrix and Jury criterion have been applied to discuss the local stability of the Nash equilibrium in this paper.

The characteristic polynomial of the Jacobian matrix is as follows:

$$
F(\lambda)=\lambda^{4}+\zeta_{3} \lambda^{3}+\zeta_{2} \lambda^{2}+\zeta_{1} \lambda+\zeta_{0}
$$

In order to guarantee the local stability of the Nash equilibrium, $F(\lambda)$ must satisfy the following conditions:

$$
\begin{aligned}
1+\zeta_{3}+\zeta_{2}+\zeta_{1}+\zeta_{0} & >0, \\
1-\zeta_{3}+\zeta_{2}-\zeta_{1}+\zeta_{0} & >0, \\
\left|\zeta_{0}\right| & <1, \\
\left|\beta_{0}\right| & <\left|\beta_{3}\right|, \\
\left|\sigma_{0}\right| & <\left|\sigma_{2}\right| .
\end{aligned}
$$

The details of $\zeta_{1}, \zeta_{2}, \zeta_{3}, \zeta_{4}, \beta_{0}, \beta_{3}, \sigma_{0}$, and $\sigma_{2}$ are as below:

$$
\begin{aligned}
& \beta_{3}=1-\zeta_{0}^{2}, \\
& \beta_{2}=\zeta_{3}-\zeta_{1} \zeta_{0}, \\
& \beta_{1}=\zeta_{3}-\zeta_{2} \zeta_{0}, \\
& \beta_{0}=\zeta_{1}-\zeta_{3} \zeta_{0}, \\
& \sigma_{2}=\beta_{3}^{2}-\beta_{0}^{2}, \\
& \sigma_{1}=\beta_{3} \beta_{2}-\beta_{1} \beta_{0}, \\
& \sigma_{0}=\beta_{3} \beta_{1}-\beta_{2} \beta_{0}
\end{aligned}
$$




$$
\begin{aligned}
& \zeta_{0}=1-2 g_{1} k_{1}-2 g_{2} k_{2}+4 g_{1} k_{1} g_{2} k_{2}-2 g_{3} w_{1}+3 g_{1} k_{1} g_{3} w_{1} \\
& +4 g_{2} k_{2} g_{3} w_{1}-6 g_{1} k_{1} g_{2} k_{2} g_{3} w_{1}-2 g_{4} w_{2}+4 g_{1} k_{1} g_{4} w_{2} \\
& +3 g_{2} k_{2} g_{4} w_{2}-6 g_{1} k_{1} g_{2} k_{2} g_{4} w_{2}+4 g_{3} w_{1} g_{4} w_{2} \\
& -6 g_{1} k_{1} g_{3} w_{1} g_{4} w_{2}-6 g_{2} k_{2} g_{3} w_{1} g_{4} w_{2} \\
& +9 g_{1} k_{1} g_{2} k_{2} g_{3} w_{1} g_{4} w_{2}-g_{1} k_{1} g_{2} k_{2} \mu^{2}-g_{2} k_{2} g_{3} w_{1} \mu^{2} \\
& +2 g_{1} k_{1} g_{2} k_{2} g_{3} w_{1} \mu^{2}-g_{1} k_{1} g_{4} w_{2} \mu^{2}+2 g_{1} k_{1} g_{2} k_{2} g_{4} w_{2} \mu^{2} \\
& -4 g_{3} w_{1} g_{4} w_{2} \mu^{2}+6 g_{1} k_{1} g_{3} w_{1} g_{4} w_{2} \mu^{2} \\
& +6 g_{2} k_{2} g_{3} w_{1} g_{4} w_{2} \mu^{2}-10 g_{1} k_{1} g_{2} k_{2} g_{3} w_{1} g_{4} w_{2} \mu^{2} \\
& +g_{1} k_{1} g_{2} k_{2} g_{3} w_{1} g_{4} w_{2} \mu^{2} \text {, } \\
& \zeta_{1}=-4+6 g_{1} k_{1}+6 g_{2} k_{2}-8 g_{1} k_{1} g_{2} k_{2}+6 g_{3} w_{1} \\
& -6 g_{1} k_{1} g_{3} w_{1}-8 g_{2} k_{2} g_{3} w_{1} \\
& +6 g_{1} k_{1} g_{2} k_{2} g_{3} w_{1}+6 g_{4} w_{2}-8 g_{1} k_{1} g_{4} w_{2}-6 g_{2} k_{2} g_{4} w_{2} \\
& +6 g_{1} k_{1} g_{2} k_{2} g_{4} w_{2}-8 g_{3} w_{1} g_{4} w_{2}+6 g_{1} k_{1} g_{3} w_{1} g_{4} w_{2} \\
& +6 g_{2} k_{2} g_{3} w_{1} g_{4} w_{2}+2 g_{1} k_{1} g_{2} k_{2} \mu^{2}+2 g_{2} k_{2} g_{3} w_{1} \mu^{2} \\
& -2 g_{1} k_{1} g_{2} k_{2} g_{3} w_{1} \mu^{2}+2 g_{1} k_{1} g_{4} w_{2} \mu^{2} \\
& -2 g_{1} k_{1} g_{2} k_{2} g_{4} w_{2} \mu^{2}+8 g_{3} w_{1} g_{4} w_{2} \mu^{2} \\
& -6 g_{1} k_{1} g_{3} w_{1} g_{4} w_{2} \mu^{2}-6 g_{2} k_{2} g_{3} w_{1} g_{4} w_{2} \mu^{2} \text {, } \\
& \zeta_{2}=6-6 g_{1} k_{1}-6 g_{2} k_{2} \\
& +4 g_{1} k_{1} g_{2} k_{2}-6 g_{3} w_{1}+3 g_{1} k_{1} g_{3} w_{1}+4 g_{2} k_{2} g_{3} w_{1} \\
& -6 g_{4} w_{2}+4 g_{1} k_{1} g_{4} w_{2}+3 g_{2} k_{2} g_{4} w_{2}+4 g_{3} w_{1} g_{4} w_{2} \\
& -g_{1} k_{1} g_{2} k_{2} \mu^{2}-g_{2} k_{2} g_{3} w_{1} \mu^{2}-g_{1} k_{1} g_{4} w_{2} \mu^{2} \\
& -4 g_{3} w_{1} g_{4} w_{2} \mu^{2} \text {, } \\
& \zeta_{3}=-4+2 g_{1} k_{1}+2 g_{2} k_{2}+2 g_{3} w_{1} \\
& +2 g_{4} w_{2} \text {. }
\end{aligned}
$$

Because the conditions are very complex, the process to solve (12) is a tedious task. If the Nash equilibrium satisfies (12), it can be considered as locally stable. In the next section, we will utilize numerical simulation to further analyze the dynamic characteristic on the system.

\section{Dynamic Characteristics of the System}

Recently, the numerical simulation method has been widely applied to represent complex dynamic system in literatures. In this study, $g_{i}(i=1,2)$ is the sales commissions' adjustment speed of retailer $i . g_{i}(i=3,4)$ represents the adjustment speed of the wholesale prices $\left(w_{1}, w_{2}\right)$ of the manufacturer. The values of the system parameters are defined as $k_{1}=0.1$, $k_{2}=0.1, w_{1}=0.31, w_{2}=0.4, g_{1}=0.4, g_{2}=0.13, g_{3}=0.12$, $g_{4}=0.15, \mu=0.5$, and $\eta=1.1$. The stable region, bifurcation, and chaos will be studied as follows.

3.1. The Stable Region. The decision variables of the system are wholesale prices and sales commissions. The system will change to be either stable or unstable, if the wholesale prices and sales commissions obtain different values. The stability region of the deterministic system is shown as the blue and green part in Figures 2 and 3, respectively. The white areas

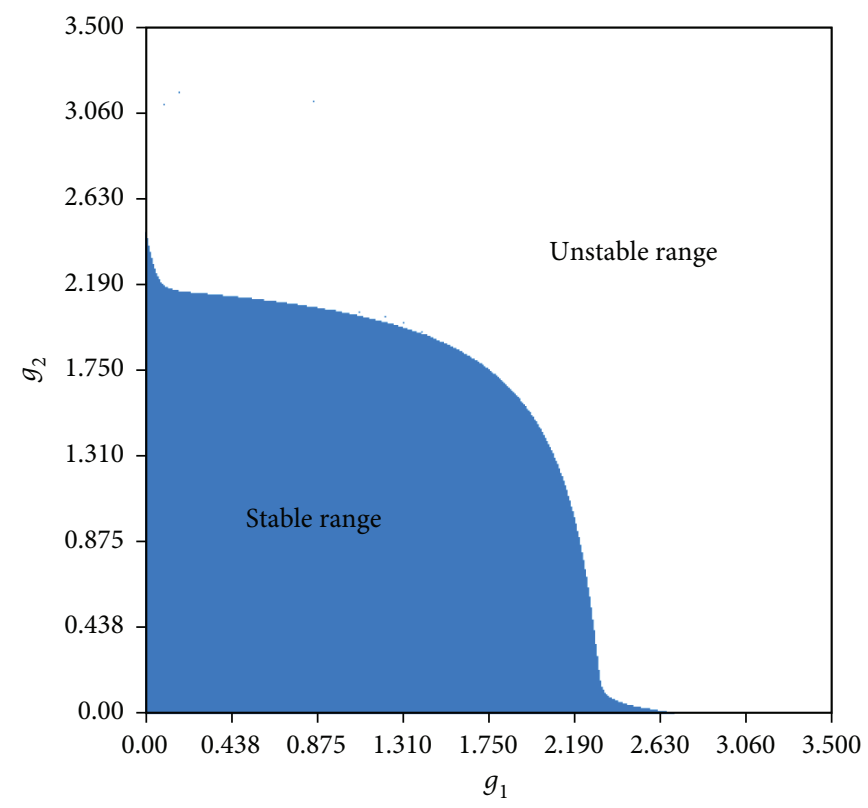

FIgURE 2: The 2D stable region of $g_{1}$ and $g_{2}$.

are the unstable range. If the applied values come from the blue and green region of Figures 2 and 3, after the iteration of period by period, the system will tend to reach the equilibrium state. If the values landed in the white areas, the system will exhibit unstable phenomena.

In Figure 2, when $g_{1}$ increases, the tendency of $g_{2}$ should be reduced. In the stable region, it has the opposite effect on $g_{1}$ and $g_{2}$, so does Figure 3. Through Figures 2 and 3, we found that the stable range of $g_{1}$ and $g_{2}$ is almost twice as much as $g_{3}$ and $g_{4}$, when the value of $g_{1}$ is larger than others' price adjustment parameters. Period doubling and chaos should be avoided. The supply chain system should be kept in the stable state as long as possible.

3.2. The Bifurcation and Chaos Behavior. The parameter basin has been used to describe $2 \mathrm{D}$ bifurcation effect. The results are shown in Figures 4 and 5. Different colors represent different cycles. Blue represents the stable region in Figure 4, and green represents the stable region in Figure 5. Orange, pink, purple, indigo, brown, yellow, and black regions represent the stable cycles of the periods from 2 to 8 , respectively. The gray region is non-convergence, and the white region is divergence in both Figures 4 and 5 . The system can remain stable, when the adjustment parameter $g_{i}$ is relatively small. As $g_{1}$ and $g_{2}$ increase, the system will go into the stable cycles of period 2. If $g_{1}$ and $g_{2}$ continue to increase, the system will go into the stable cycles of period 4 , which is shown in Figure 4. However, the system continually changes to the stable cycles of periods $2,4,8$, and so on. If $g_{3}$ and $g_{4}$ keep on increasing, the system will go into chaos state. This process is depicted in Figure 5. In this situation, the market will become chaotic and the market participants cannot make good decisions to reach the best profits.

When the adjustment parameter changes in a small range from 0 , the variables will be stable. However, if the decision 


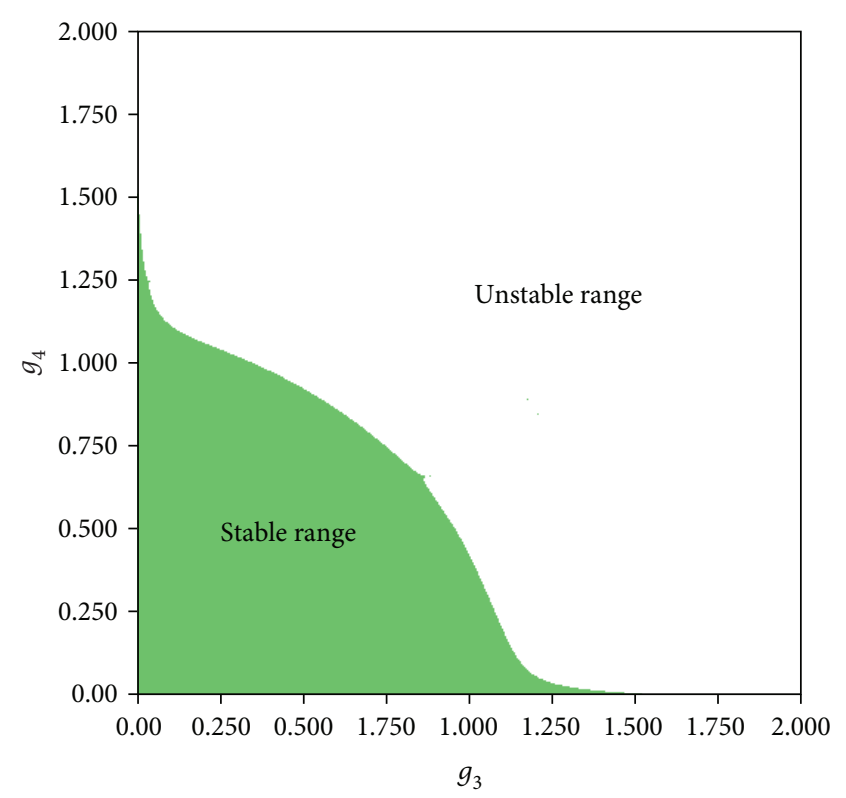

FIgURE 3: The 2D stable region of $g_{3}$ and $g_{4}$.

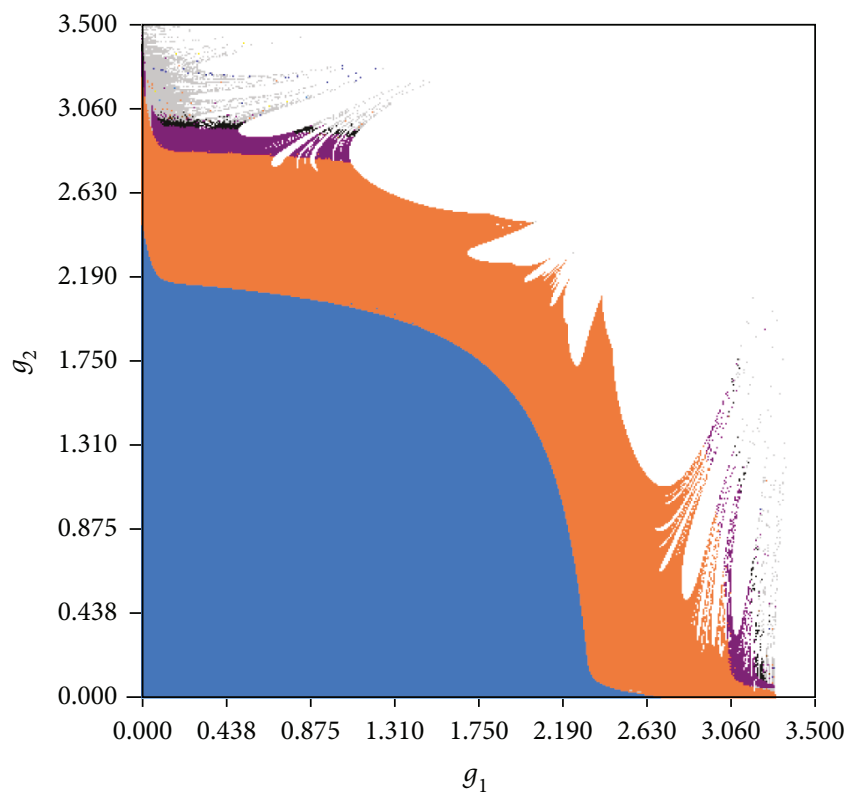

Figure 4: 2D bifurcation diagram of $g_{1}$ and $g_{2}$.

variables adjust sharply, the variables will be unstable. Especially, in chaotic state, the system will become sensitive and unpredictable. In economic terms, when the adjustment parameter exceeds a certain limit, the intense competition and price drastic fluctuation will occur.

The bifurcation diagram is an intuitive way to show the dynamic characteristics of the system. One of the parameters is fixed and the other changed within a certain range. In the following bifurcation diagrams, the blue line represents $k_{1}$ and the red line $k_{2}$. The green line represents $w_{1}$ and the purple line $w_{2}$.

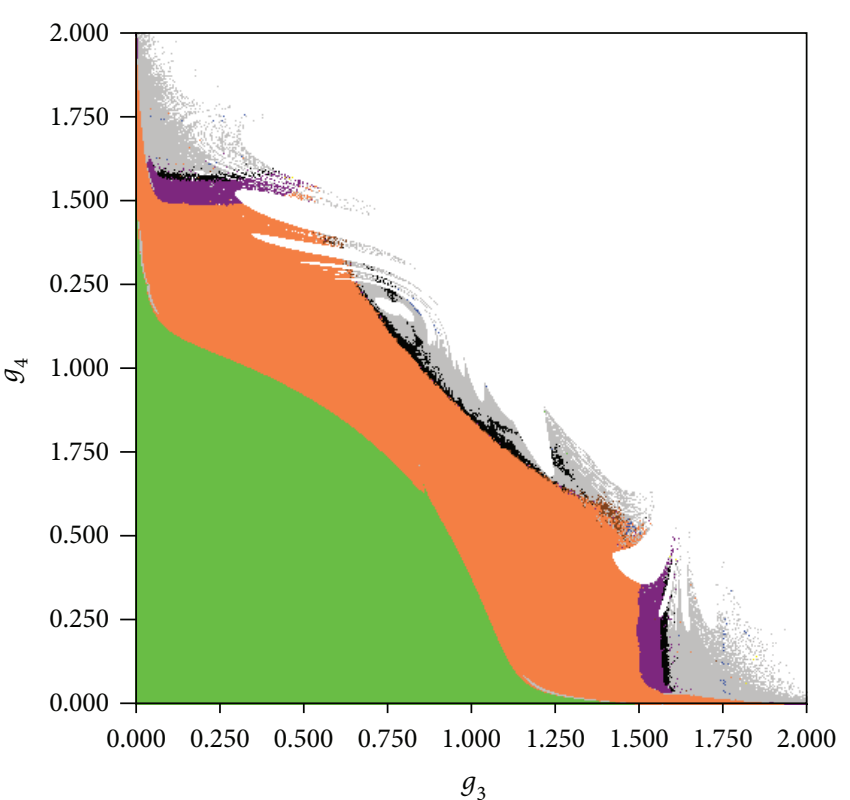

Figure 5: 2D bifurcation diagram of $g_{3}$ and $g_{4}$.

The largest Lyapunov exponent (LLE) is another efficient way to make clear the complex dynamic characteristics of the system, which also is corresponding to the variation of the bifurcation diagram when discussing the same parameter. The dramatic variation of LLE is accompanied by the decision variables changing. If the $\operatorname{LLE}<0$, it means the system is in a stable state. When the LLE $=0$ for the first time, the system stays at a critical point and usually the bifurcation appears. If the $L L E>0$, it indicates that the system runs into the unstable state. The manufacturer and retailers should be cautious to prevent system chaos.

The following part gives the bifurcation diagram and LLE diagram with respect to the parameters $g_{1}, g_{2}, g_{3}$, and $g_{4}$. The bifurcation diagrams of $k_{1}, k_{2}, w_{1}$, and $w_{2}$, with respect to the adjustment speeds of the sales commissions, are shown in Figures 6 and 7. In the same condition, Figures 8 and 9 depict the variation of LLE with respect to $g_{1}$ and $g_{2}$.

When $g_{1} \in[1.5,3.10]$ and with the other parameters settled down, the conditions of $k_{1}, k_{2}, w_{1}$, and $w_{2}$ are shown in Figure 6. Because the dots of $w_{1}$ and $w_{2}$ gather together, we further enlarge critical parts in sub-windows in order to describe the bifurcation conditions of $w_{1}$ and $w_{2}$. The upper small picture is the blowup of the bifurcation diagram for $w_{1}$ and $w_{2}$, and the other one is the blowup of the bifurcation diagram for $k_{2}$. When $g_{1} \in[0,2.338], k_{1}, k_{2}, w_{1}$, and $w_{2}$ are all in the stable state. When $g_{1}$ grows to $2.339, k_{1}, k_{2}, w_{1}$, and $w_{2}$ bifurcate at the first time and enter into the stable cycles of period 2 . If $g_{1}$ continues to increase, the system will enter into the stable cycles of period 4 .

Figure 8 reveals the variation of LLE along with $g_{1}$ increasing, which expresses the pattern of the complex dynamic behavior caused by the growth of the price adjustment speed. Figure 8 explores the LLE of the system with respect to $g_{1} \in[1.5,3.10]$. When $g_{1} \in[0,2.338]$, the LLE is below zero, which indicates that the system is stable. When 


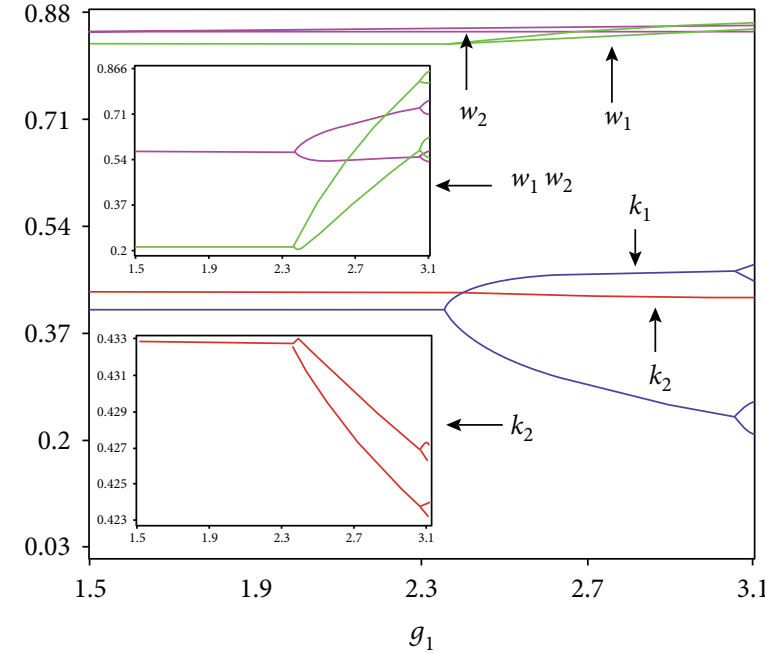

Figure 6: Bifurcation diagram of $k_{1}, k_{2}, w_{1}, w_{2}$ when $g_{1} \in[1.5,3.10]$.

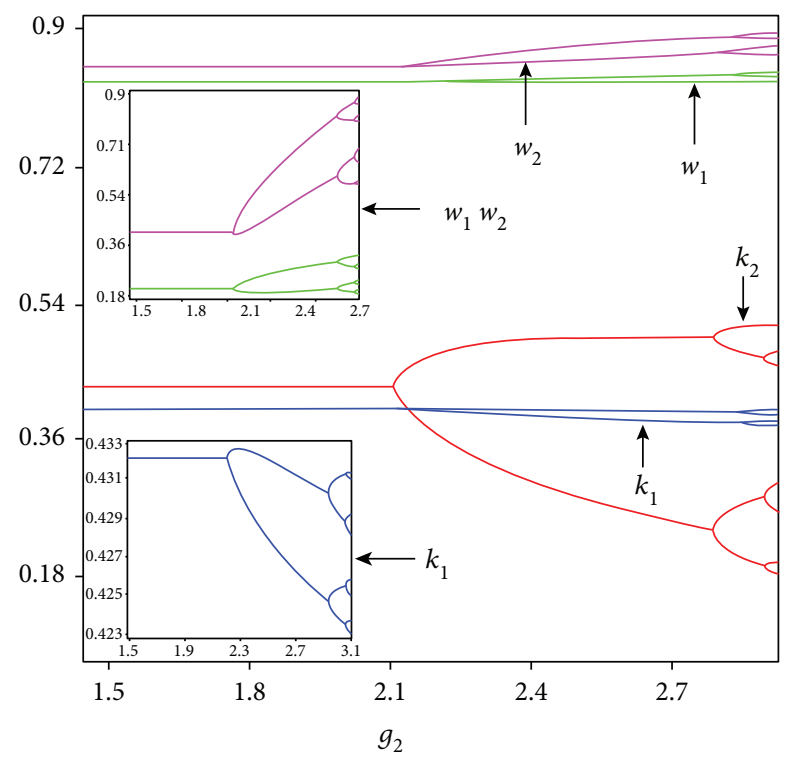

FiguRE 7: Bifurcation diagram of $k_{1}, k_{2}, w_{1}, w_{2}$ when $g_{2} \in[1.5,2.98]$.

$g_{1}$ increases to 2.339 , the LLE is equal to zero and the bifurcation occurs in the system. The bifurcation point in Figure 8 is the same as that in Figure 6.

Figures 7 and 9 also have the same bifurcation point. $k_{1}$, $k_{2}, w_{1}$, and $w_{2}$ bifurcate at 2.156 as $g_{2}$ varies from 0 to 2.98 . If $g_{2}$ continues increasing, the system runs into the cycles of period 4. In order to describe the changing processes of the system from the stable state to the chaotic region more clearly, $g_{1}$ and $g_{2}$ start from 1.5 in Figures 6-9.

The bifurcation diagrams of $k_{1}, k_{2}, w_{1}$, and $w_{2}$, with respect to the adjustment speeds of the wholesale prices, are shown in Figures 10 and 11. In the same condition, Figures 12 and 13 depict the variation of LLE with respect to $g_{3}$ and $g_{4}$.

$k_{1}, k_{2}, w_{1}$, and $w_{2}$ bifurcate at 1.096 as $g_{3}$ varies from 0 to 1.70. $k_{1}, k_{2}, w_{1}$, and $w_{2}$ bifurcate at 1.107 as $g_{4}$ varies from 0 to 1.73 . If $g_{3}$ and $g_{4}$ continue increasing, the system runs into

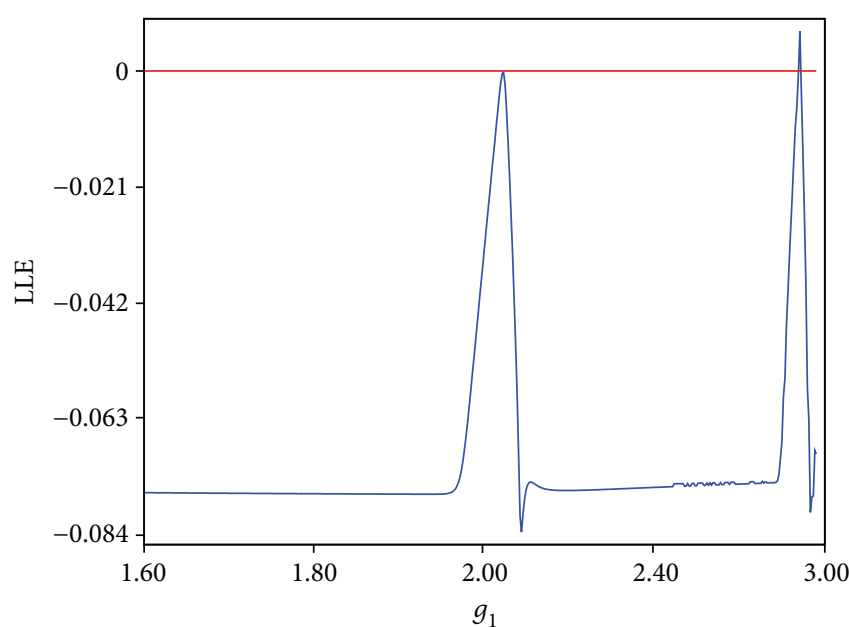

FIgURE 8: The largest Lyapunov exponent of the system with respect to $g_{1} \in[1.5,3.10]$.

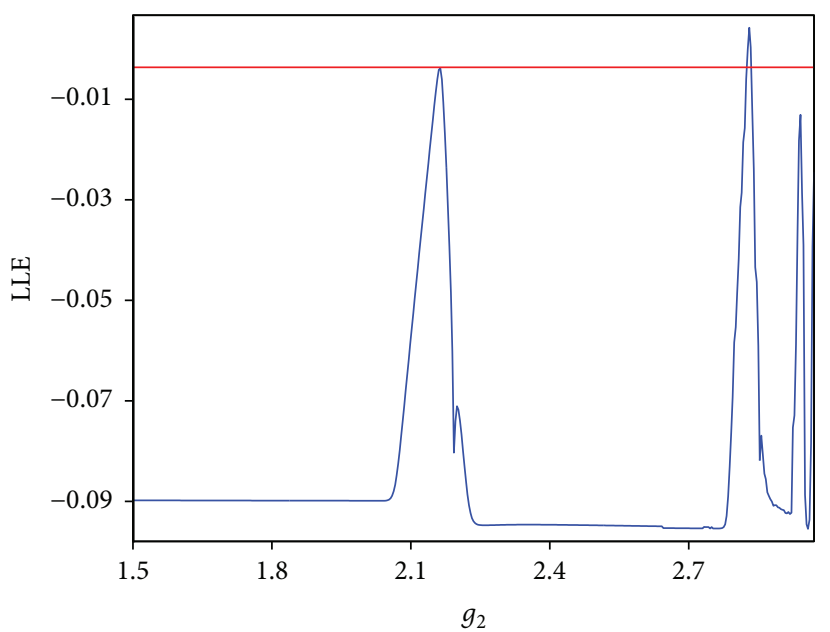

FIGURE 9: The largest Lyapunov exponent of the system with respect to $g_{2} \in[1.5,2.98]$.

cycles of periods 4,8 , and so on. Next, the system will fall into chaos gradually. In this part, $g_{3}$ and $g_{4}$ start from 0.7 in Figures 10-13.

Above all, Figures 10-13 sufficiently indicate that if the wholesale prices of the manufacturer are adjusted drastically, the system will fall into chaos. On the other side, as shown in Figures 6-9, if the sales commissions of the retailers are adjusted radically, the bifurcation will appear but the chaos will not occur. From an economic point of view, if the adjustment parameter rapidly changes, the market will fall into the chaotic state. Therefore, the manufacturer and retailers should keep the price adjustments within a reasonable range.

The substitutability of the retailers will be discussed in the following part. $\mu=0$ represents the demands which are absolutely independent. Each retailer is a monopolist in its own area. $\mu=1$ represents the two retailers who are totally substitutable. When $\mu \in[0,0.89]$ and the other parameters are kept constant, the situations of $k_{1}, k_{2}, w_{1}$, and $w_{2}$ are shown in Figure 14 . When $\mu$ grows to 0.872 , the system begins the first 


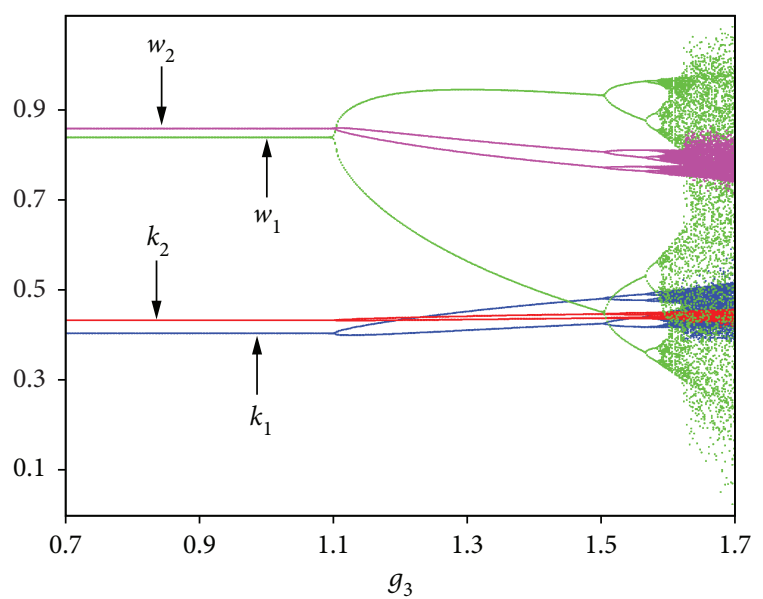

FIGURE 10: Bifurcation diagram of $k_{1}, k_{2}, w_{1}, w_{2}$ when $g_{3} \in[0.7$, $1.70]$.

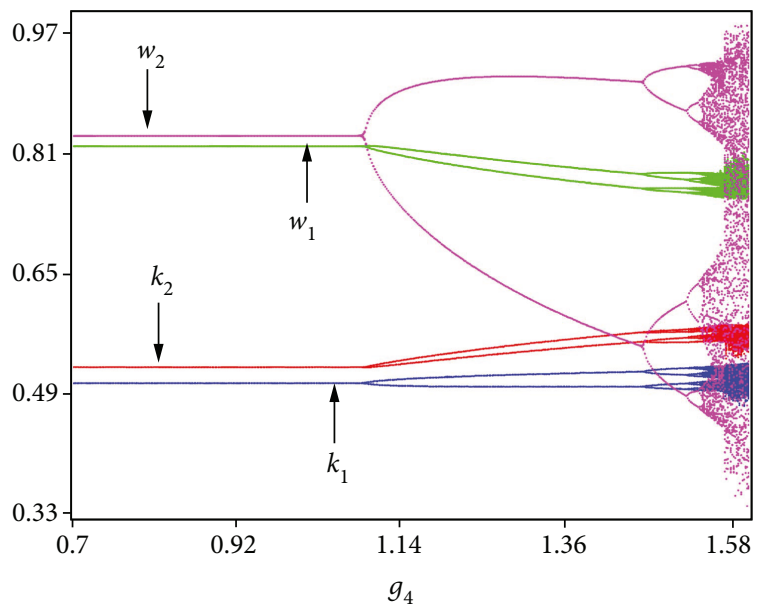

Figure 11: Bifurcation diagram of $k_{1}, k_{2}, w_{1}, w_{2}$ when $g_{4} \in[0.7$, $1.73]$.

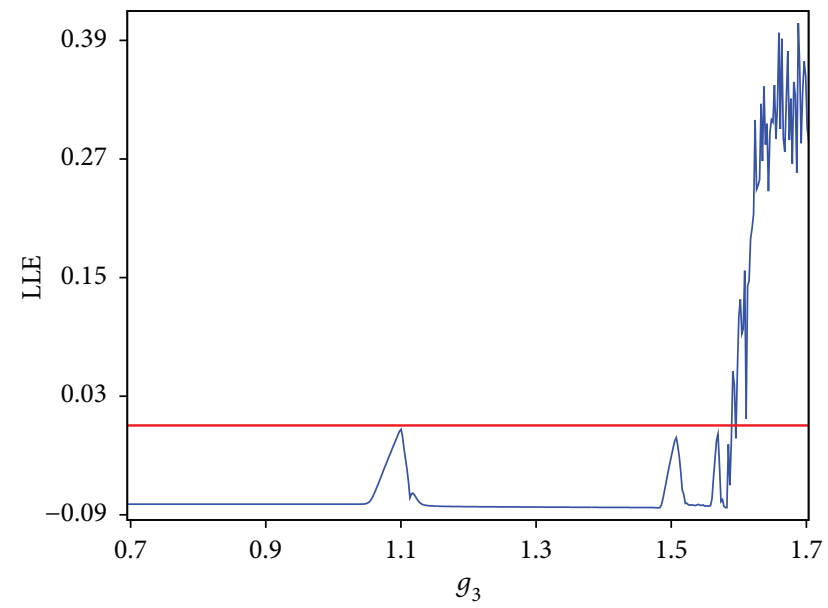

FIGURE 12: The largest Lyapunov exponent of the system with respect to $g_{3} \in[0.7,1.70]$.

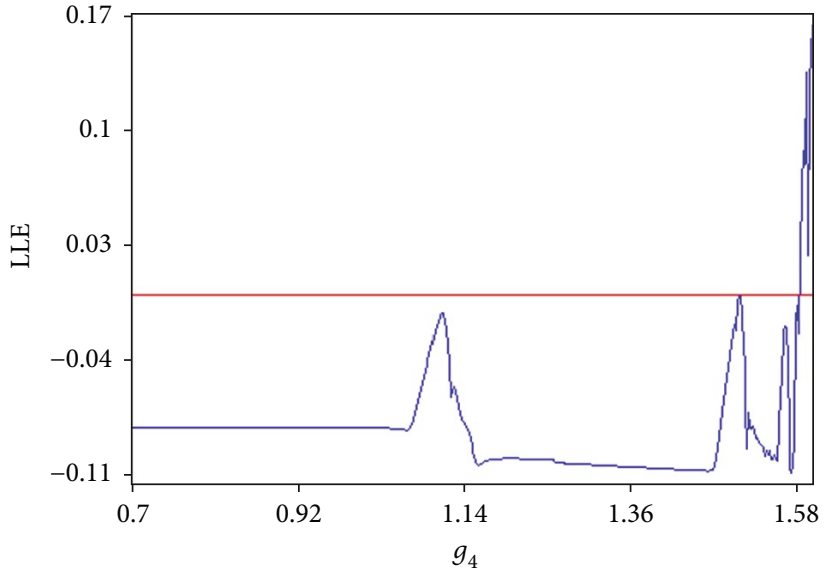

FIgure 13: The largest Lyapunov exponent of the system with respect to $g_{4} \in[0.7,1.73]$.

bifurcation which is the stable cycles of period 2 . If $\mu$ continues to increase, the system runs into the stable cycles of periods 4 , 8 , and so on. Then, the system will fall into chaos gradually. The small picture in Figure 14 is the blowup of the bifurcation region for $k_{1}, k_{2}, w_{1}$, and $w_{2}$, when $\mu \in[0.8,0.89]$.

Figure 15 explores the LLE of the system with respect to $\mu \in[0,0.89]$. When $\mu \in[0,0.871]$, the LLE is less than zero, and the system is in a stable state. While $\mu$ grows to 0.872 , LLE changes into zero for the first time, and the system falls into the bifurcation state, the completely same bifurcation points in Figures 15 and 14.

In Figure 14, the manufacturer is more sensitive to the substitutability of the retailer, which leads to a rise in the wholesale price. However, the retailer's profits are robust to the changes in the retailer's substitutability. Under this condition, fierce competition may lead to the dominance of the manufacturer. Nevertheless, bifurcation and chaos will still occur in the market after the fierce competition, once a certain extent of substitutability remains among the retailers of different channels.

The impacts of consumer's channel preference on the dynamic system will be discussed in the following part. When $\eta \in[0,3.80], \eta=3.80, g_{1}=0.4, g_{2}=0.4, g_{3}=0.4$, and $g_{4}=$ 0.4 , the situations of $k_{1}, k_{2}, w_{1}$, and $w_{2}$ are shown in Figure 16. The lines in the bifurcation diagram indicate that other parameters are stabilized separately, when $\eta$ is changing in the range of $[0,3.80]$. When $\eta$ grows to 2.558 , the system begins the first bifurcation which is the stable cycles of period 2. If $\eta$ continues to increase, the system runs into the stable cycles of periods 4,8 , and so on. After that, the system will fall into chaos gradually. Figure 17 proves the same conclusion as Figure 16 does.

The curves of the traditional retailers and online retailers are shown in Figure 16. When $\eta>1$, it can be found that the channel preference of consumers will convert from one channel to another. If one channel has more consumer preference, its wholesale prices and sales commission will rise; $w_{2}>w_{1}$ and $k_{2}>k_{1}$ are displayed in Figure 16. However, if the channel preference obviously comes to one channel, it is possible that bifurcation and chaos appear in the system. 


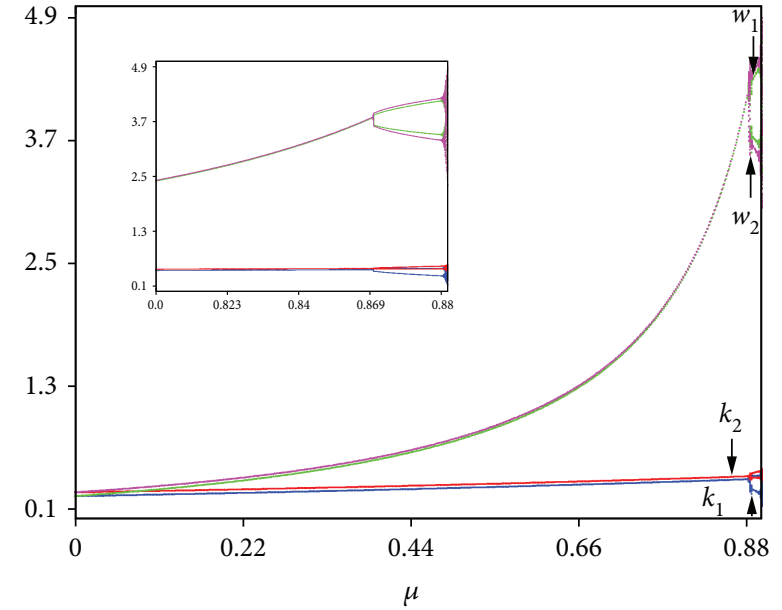

FIGURE 14: Bifurcation diagram of $k_{1}, k_{2}, w_{1}, w_{2}$ when $\mu \in[0,0.89]$.

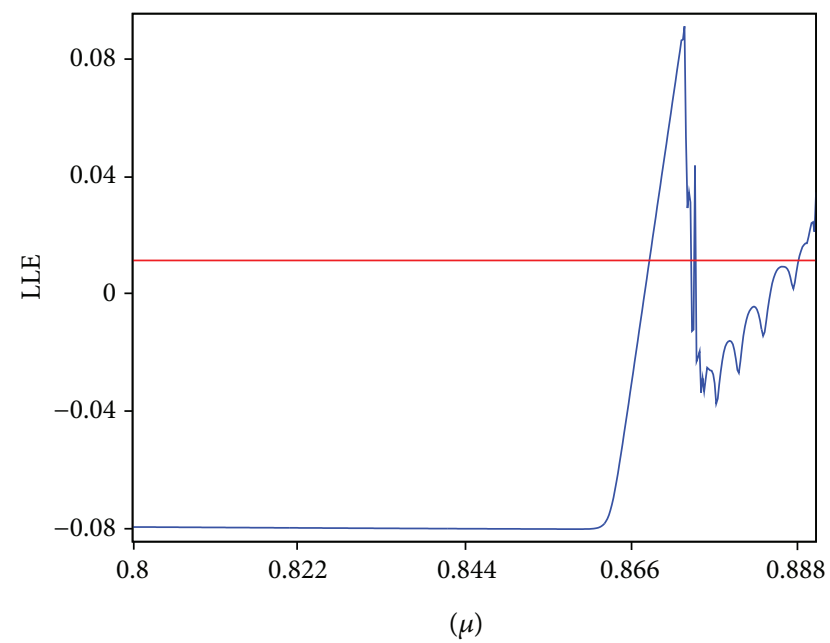

FIGURE 15: The largest Lyapunov exponent of the system with respect to $\mu \in[0.8,0.89]$.

In this paper, the chaos attractor has been investigated to the dynamic characteristics of the system. Strange attractor is a set of numbers of indefinite points. The larger the space of the strange attractor is, the more complex the structure will be. No matter how instable the system is, the points are always attracted along a certain trajectory.

Figure 18 shows the chaotic attractor of $w_{1}$ and $w_{2}$, when $k_{1}=0.31, k_{2}=0.1, w_{1}=0.31, w_{2}=0.4, g_{1}=0.4, g_{2}=0.13$, $g_{3}=1.65, g_{4}=0.15, \mu=0.5$, and $\eta=1.1$, the system becomes complex and even moves into chaotic state. The dynamic characteristics of the system are obvious. Based on parameter studies, $w_{1}$ changes in a larger range than $w_{2}$ when the adjustment speeds of wholesale price $g_{3}$ change more intensively than $g_{4}$.

The time series of different decision variables are shown in Figures 19 and 20. In the chaotic state, the system is more sensitive to the initial value. The phenomenon can be called as the initial value sensitivity. In Figure 19, to better show the character of the chaotic system, we assume the retailer 1 to make decisions under the condition that

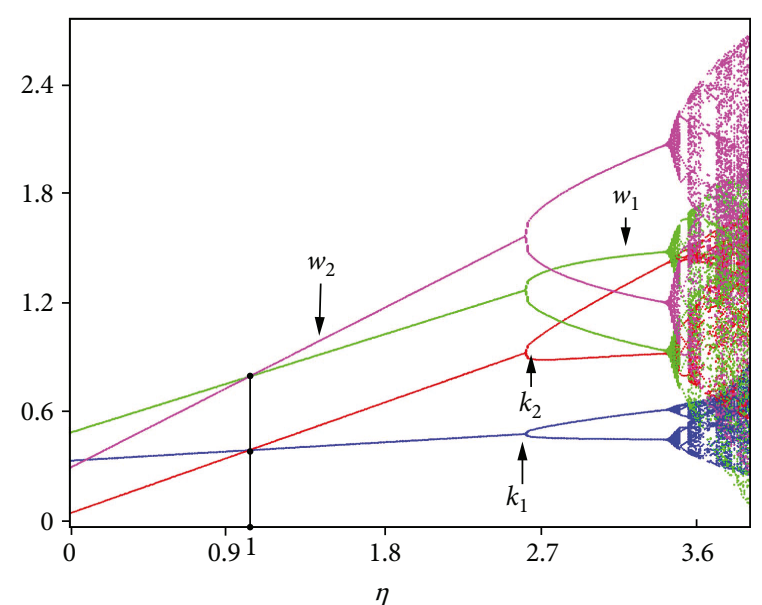

FIGURE 16: Bifurcation diagram of $k_{1}, k_{2}, w_{1}, w_{2}$ when $\eta \in[0,3.80]$.

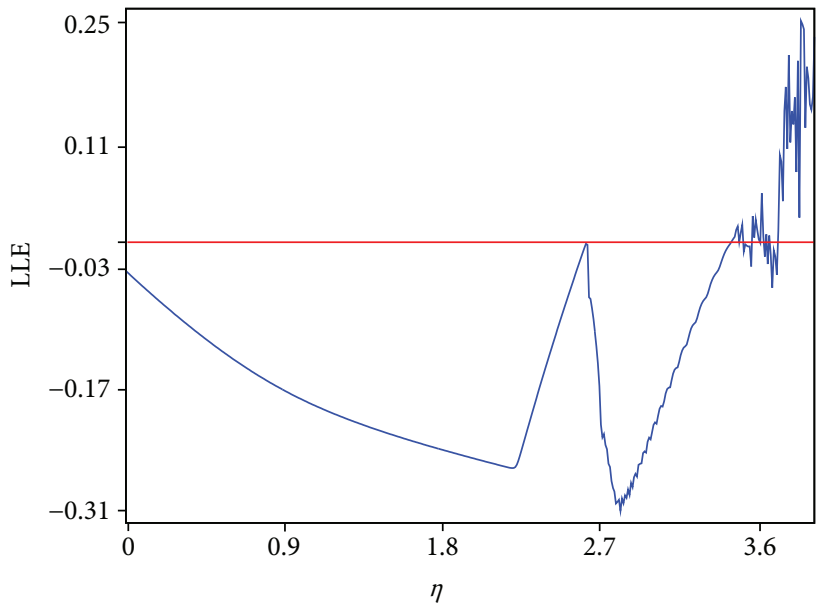

FIgURE 17: The largest Lyapunov exponent of the system with respect to $\eta \in[0,3.80]$.

$\eta=3.75$ and show the time series of $k_{1}$ after 100 iterations. The blue line represents the initial value with $k_{1}=0.1$, and the red line represents the initial value with $k_{1}=0.101$, when the dynamic system state is in a chaotic state. We also set the other parameters' values as follows: $k_{2}=0.1$, $w_{1}=0.31, w_{2}=0.4, g_{1}=0.4, g_{2}=0.4, g_{3}=0.4, g_{4}=0.4$, and $\mu=0.5$. As shown in Figure 19, although the initial value of sales commissions only changes from 0.1 to 0.101 , after 100 iterations, a large gap between the two tracks will occur.

Figure 20 shows the time series of $k_{1}, k_{2}, w_{1}$, and $w_{2}$ in a stable state. We set the initial values of the wholesale prices and sales commissions as $k_{1}=0.3, k_{2}=0.6, w_{1}=1$, and $w_{2}$ $=0.5$ in Figure 20. We set the initial value of $k_{1}$ and $w_{2}$ from a low value, while we set the initial value of $k_{2}$ and $w_{1}$ from a high value. We set the same initial values of $k_{1}, k_{2}, w_{1}$, and $w_{2}$ with those above. $k_{1}, k_{2}, w_{1}$, and $w_{2}$ would gradually flatten after 12 iterations shown in Figure 20.

In short, Figures 19 and 20 have different meanings. The adjustment speeds of the wholesale prices and sales commissions depend on the price fluctuation levels. As 


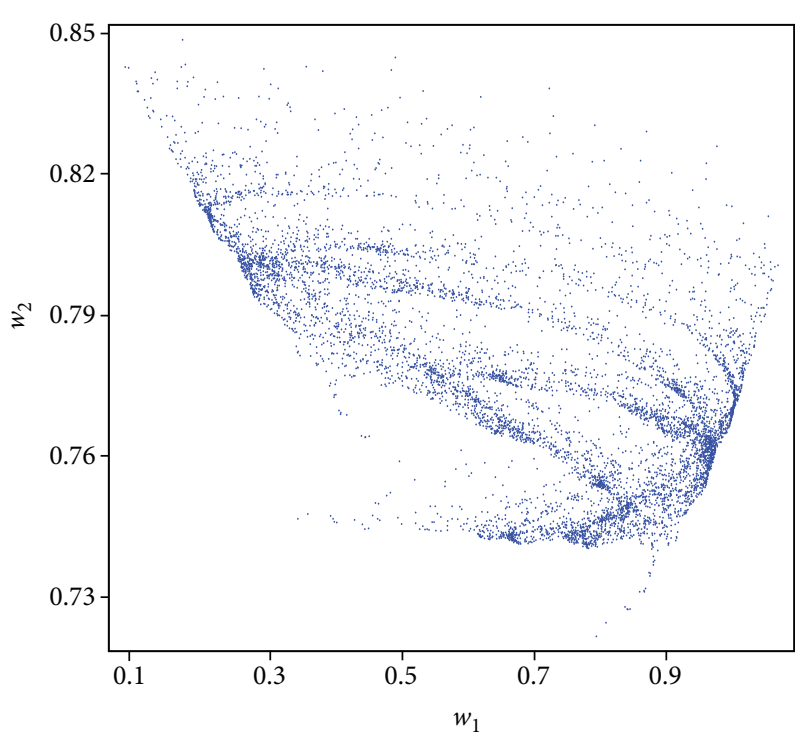

FIgURE 18: The chaotic attractor of $w_{1}$ and $w_{2}$.

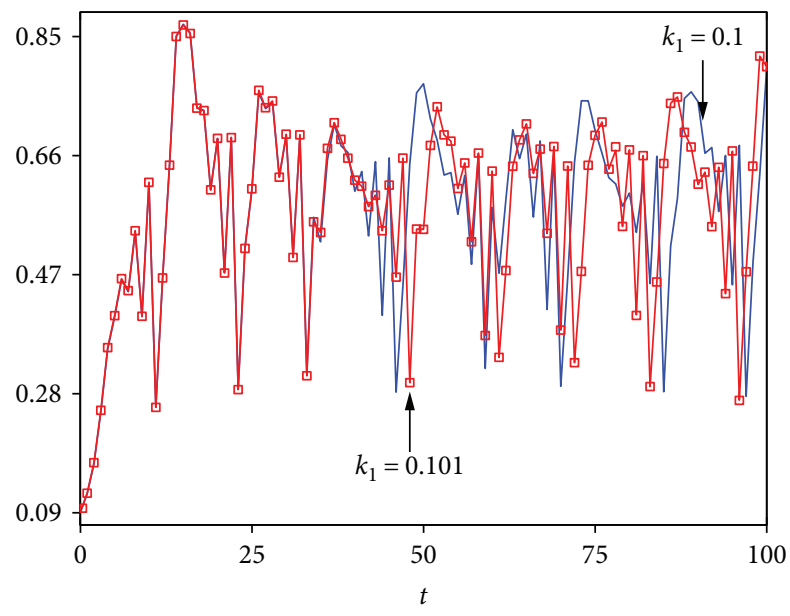

Figure 19: Time series of $k_{1}$ in a chaotic state.

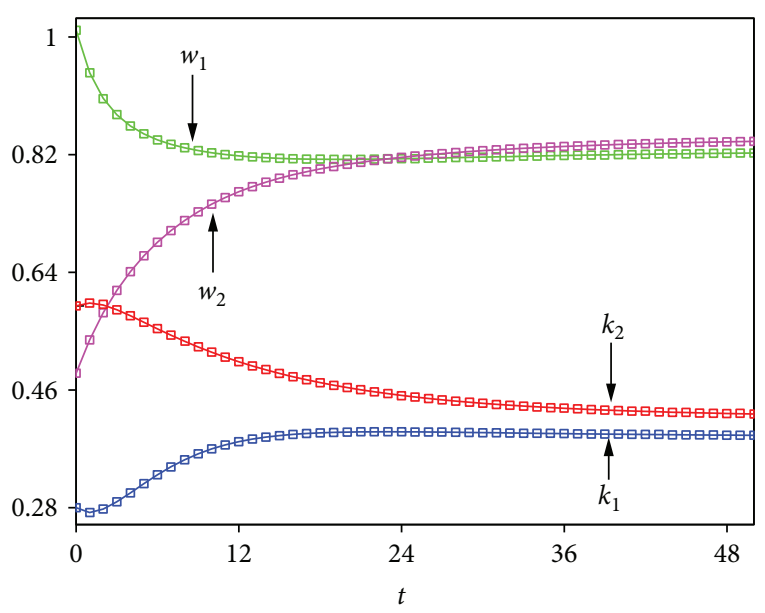

Figure 20: Time series of $k_{1}, k_{2}, w_{1}, w_{2}$ in a stable state. such, the manufacturer and retailers should keep price adjustment in reasonable ranges.

\section{Chaos Control}

The excessive competition will cause the chaotic phenomenon of a market, which poises negative effect on all competitive subjects in the market and impedes the economic operation. Therefore, some chaos control methods have been made use of to propel the system to return to stable equilibrium. There are a lot of chaos control methods such as continuous feedback control, self-adaptation control, and OGY. In this research, parameter adjustment control method has been used. The manager can control the chaotic behavior through introducing the control parameter $v$. Huang [23] conducted the chaos control with setting the control parameter as $v=0.6$. The values of the other parameters have been set in the sections above. The stable range and the bifurcation diagram will be given to account for the state of the system. Under the parameter adjustment control, the system can be expressed as follows:

$$
\begin{aligned}
k_{1}(t+1)= & (1-v)\left(k_{1}(t)+g_{1} k_{1}\left(1-2 k_{1}-w_{1}+\left(k_{2}+w_{2}\right) \mu\right)\right) \\
& +v k_{1}(t) \\
k_{2}(t+1)= & (1-v)\left(k_{2}(t)+g_{2} k_{2}\left(-2 k_{2}-w_{2}+\eta\right.\right. \\
& \left.\left.+\left(k_{1}+w_{1}\right) \mu\right)\right)+v k_{2}(t) \\
w_{1}(t+1)= & (1-v)\left(w_{1}(t)+g_{3} w_{1}\left(1-k_{1}-2 w_{1}\right.\right. \\
& \left.\left.+w_{2} \mu+\left(k_{2}+w_{2}\right) \mu\right)\right)+v w_{1}(t) \\
w_{2}(t+1)= & (1-v)\left(w_{2}(t)+g_{4} w_{2}\left(-k_{2}-2 w_{2}+\eta+w_{1} \mu\right.\right. \\
& \left.\left.+\left(k_{1}+w_{1}\right) \mu\right)\right)+v w_{2}(t) .
\end{aligned}
$$

Under the process of chaos control, three parameters, including wholesale price, consumer's channel preference, and the substitutability of retailers, will be discussed in this part. If $g_{3}$ equals 1.65 , the system will be chaotic. When the control parameter $v$ varies from 0 to 0.7 , the changes of the system are shown in Figure 21. Besides, if $\mu$ equals 0.892 , the system will be chaotic. When the control parameter $v$ varies from 0 to 0.3 , the changes of the system are shown in Figure 22. Finally, if we set $\eta=3.8, g_{1}=0.4, g_{2}=0.4$, $g_{3}=0.4$, and $g_{4}=0.4$, the system will be chaotic. When the control parameter $v$ varies from 0 to 0.4 , the changes of system are shown in Figure 23.

The above figures indicate that the chaos of the system has been controlled when introducing the controlling parameter $v$. With $v$ increasing, the system changes from the chaotic region to the bifurcation region. When $v$ is big enough, the system will fall into the steady state. For the manufacturer and retailer, they should try their best to control the system into the stable state and maximize their profits. 

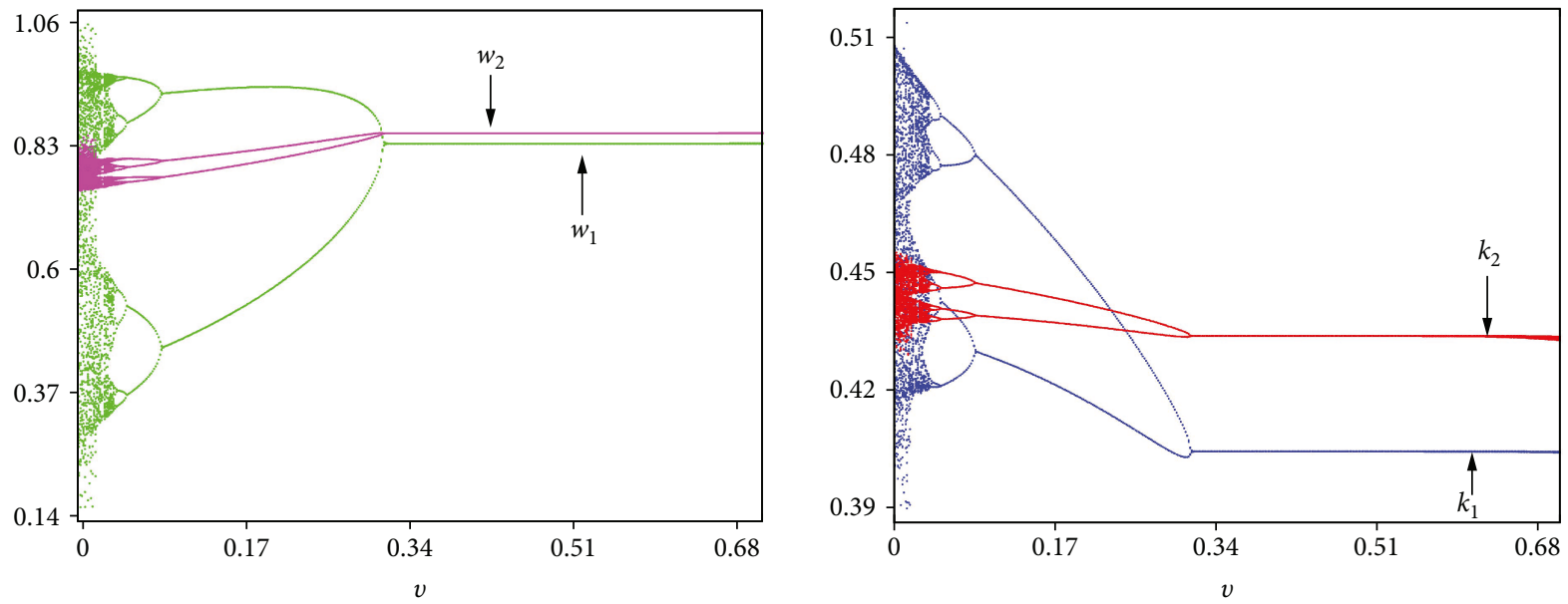

FIgURE 21: Bifurcation diagram when $v$ varies from 0 to 0.7 and $g_{3}=1.65$.
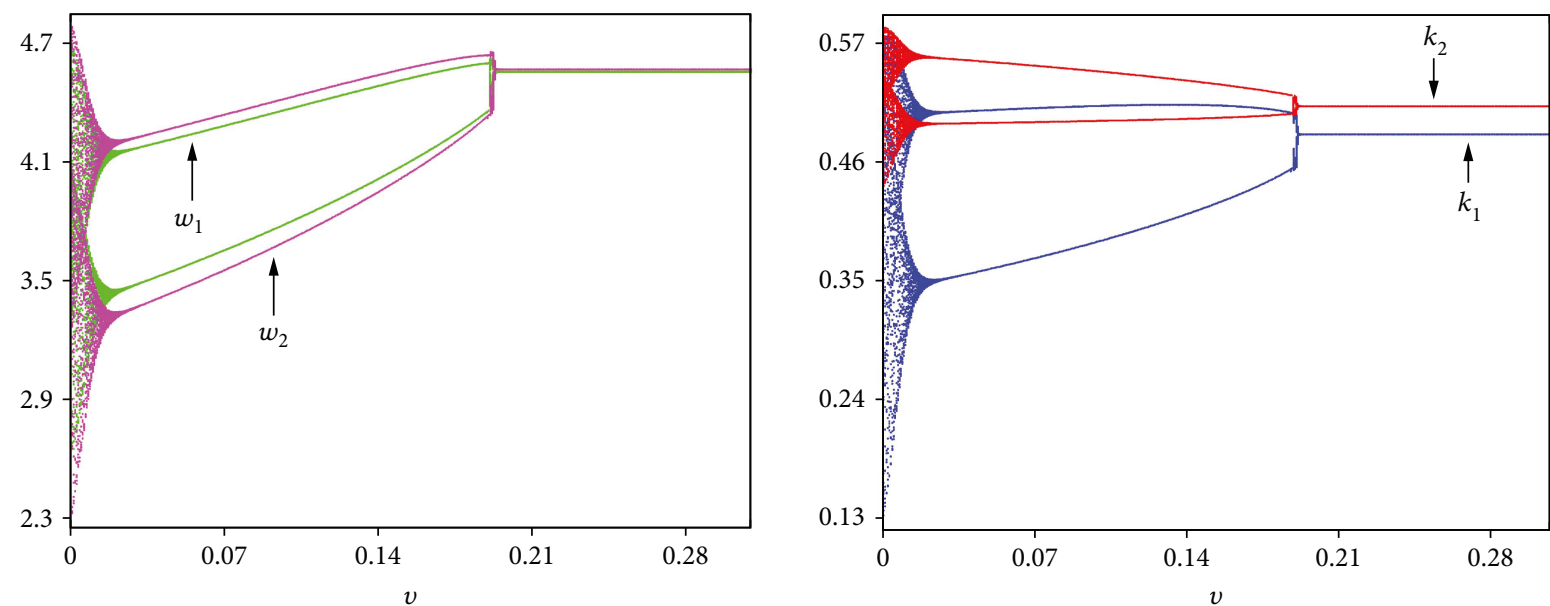

FIgURE 22: Bifurcation diagram when $v$ varies from 0 to 0.3 and $\mu=0.892$.

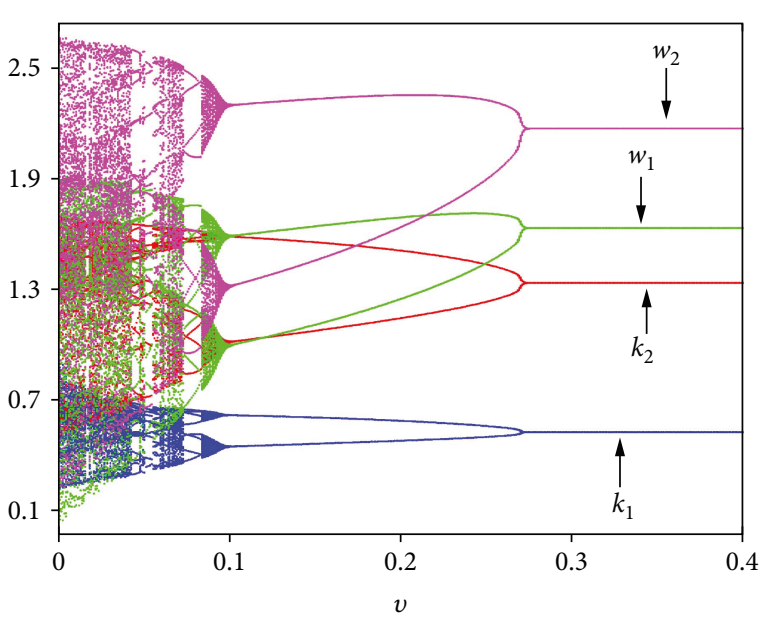

Figure 23: Bifurcation diagram when $v$ varies from 0 to 0.4 and $\eta=3.8$.

\section{Conclusion}

A supply chain system consisted of one manufacturer and two retailers have been discussed in this study. One is a traditional retailer and the other an online retailer. The complex dynamics of the system is studied by numerical simulation. The dynamic characteristics are investigated through $2 \mathrm{D}$ bifurcation diagram, the largest Lyapunov exponent, chaotic attractor, and time series. Finally, parameter adjustment control method is used to control the chaos.

In this paper, a pricing problem in the supply chain with one manufacturer who supplies an identical product to two retailers has been researched. For example, Huawei supplies Mate 9 to China Resources Vanguard Co. Ltd. and JD.com. CR Vanguard and JD.com are the typical representatives of traditional and online channels, respectively. These research results indicate that if the retailers compete with each other, the substitutability between the two sales channels will be generated. The competitions between retailers are helpful for the manufacturers. However, when the competition is 
fierce, the traditional and online channel can be replaced by each other, and the system will be reduced into a chaotic state. This article has demonstrated that consumer's channel preference can affect the wholesale prices and sales commissions. If the consumers prefer any channel of the two, its wholesale prices and sales commissions may be raised. When the preference is too intense, the system will be unstable and even lead to chaotic phenomena. The parameter adjustment control method is performed on the parameters of wholesale price; the substitution of retailers and consumer's channel preference make the system stable by adjusting the parameter $v$. For all these works, the achievements of this study have both theoretical and practical significances for the manufacturer and retailers.

The conclusions of this paper can be helpful to the managers; however, there still exist some limitations. On the one hand, it considered a model of two-stage and dual-channel supply chain, which might be simple in practice. On the other hand, we only did the numerical simulation but did not make an empirical analysis of influence factors as an example. Hence, in the future, research based on large amounts of real data is significant. We may do further study in multi-stage and multi-channel supply chains in a practical market.

\section{Data Availability}

The data used to support the findings of this study are available from the corresponding author upon request.

\section{Conflicts of Interest}

The authors declare no conflict of interest regarding the publication of this paper.

\section{Acknowledgments}

The research was supported by the National Natural Science Foundation of China (71571131).

\section{References}

[1] J. Ma and X. Ma, "Measure of the bullwhip effect considering the market competition between two retailers," International Journal of Production Research, vol. 55, no. 2, pp. 313-326, 2016.

[2] J. Ma and B. Bao, "Research on bullwhip effect in energyefficient air conditioning supply chain," Journal of Cleaner Production, vol. 143, no. 2, pp. 854-865, 2017.

[3] T. Shu, H. Liao, S. Chen, S. Wang, K. K. Lai, and L. Gan, "Analysing remanufacturing decisions of supply chain members in uncertainty of consumer preferences," Applied Economics, vol. 48, no. 34, pp. 3208-3227, 2016.

[4] L. Feng, K. Govindan, and C. Li, "Strategic planning: design and coordination for dual-recycling channel reverse supply chain considering consumer behavior," European Journal of Operational Research, vol. 260, no. 2, pp. 601612, 2017.

[5] S. Du, J. Zhu, H. Jiao, and W. Ye, "Game-theoretical analysis for supply chain with consumer preference to low carbon,"
International Journal of Production Research, vol. 53, no. 12, pp. 3753-3768, 2014.

[6] R. T. Frambach, H. C. A. Roest, and T. V. Krishnan, "The impact of consumer internet experience on channel preference and usage intentions across the different stages of the buying process," Journal of Interactive Marketing, vol. 21, no. 2, pp. 26-41, 2007.

[7] M. Okimoto, "International price competition among food industries: the role of income, population and biased consumer preference," Economic Modelling, vol. 47, pp. 327-339, 2015.

[8] M. Khouja, S. Park, and G. Cai, "Channel selection and pricing in the presence of retail-captive consumers," International Journal of Production Economics, vol. 125, no. 1, pp. 84-95, 2010.

[9] F. Gao and X. Su, "Omnichannel retail operations with buyonline-and-pick-up-in-store," Management Science, vol. 63, no. 8, pp. 2478-2492, 2017.

[10] H. Ke and J. Liu, "Dual-channel supply chain competition with channel preference and sales effort under uncertain environment," Journal of Ambient Intelligence and Humanized Computing, vol. 8, no. 5, pp. 781-795, 2017.

[11] S. S. Gan, I. N. Pujawan, Suparno, and B. Widodo, "Pricing decision for new and remanufactured product in a closedloop supply chain with separate sales-channel," International Journal of Production Economics, vol. 190, pp. 120-132, 2017.

[12] J. Ma and H. Wang, "Complexity analysis of dynamic noncooperative game models for closed-loop supply chain with product recovery," Applied Mathematical Modelling, vol. 38, no. 23, pp. 5562-5572, 2014.

[13] Y. Song and X. Zhao, "A newsvendor problem with boundedly rational strategic customers," International Journal of Production Research, vol. 55, no. 1, pp. 228-243, 2016.

[14] J. Ma and F. Si, "Complex dynamics of a continuous Bertrand duopoly game model with two-stage delay," Entropy, vol. 18, no. 7 , p. $266,2016$.

[15] J. Ma and L. Xie, “The comparison and complex analysis on dual-channel supply chain under different channel power structures and uncertain demand," Nonlinear Dynamics, vol. 83, no. 3, pp. 1379-1393, 2016.

[16] J. Ma and L. Xie, "The impact of loss sensitivity on a mobile phone supply chain system stability based on the chaos theory," Communications in Nonlinear Science and Numerical Simulation, vol. 55, pp. 194-205, 2018.

[17] E. J. Anderson and Y. Bao, "Price competition with integrated and decentralized supply chains," European Journal of Operational Research, vol. 200, no. 1, pp. 227-234, 2010.

[18] C. H. Wu, C. W. Chen, and C. C. Hsieh, "Competitive pricing decisions in a two-echelon supply chain with horizontal and vertical competition," International Journal of Production Economics, vol. 135, no. 1, pp. 265-274, 2012.

[19] S. L. Yang and Y. W. Zhou, "Two-echelon supply chain models: considering duopolistic retailers different competitive behaviors," International Journal of Production Economics, vol. 103, no. 1, pp. 104-116, 2006.

[20] S. C. Choi, "Price competition in a channel structure with a common retailer," Marketing Science, vol. 10, no. 4, pp. 271296, 1991.

[21] T. W. Mcguire and R. Staelin, "An industry equilibrium analysis of downstream vertical integration," Marketing Science, vol. 2, no. 2, pp. 161-191, 1983. 
[22] T. Xiao, T. M. Choi, and T. C. E. Cheng, "Product variety and channel structure strategy for a retailer-Stackelberg supply chain," European Journal of Operational Research, vol. 233, no. 1, pp. 114-124, 2014.

[23] W. Huang, "Stabilizing nonlinear dynamical systems by an adaptive adjustment mechanism," Physical Review E, vol. 61, no. 2, pp. R1012-R1015, 2000. 


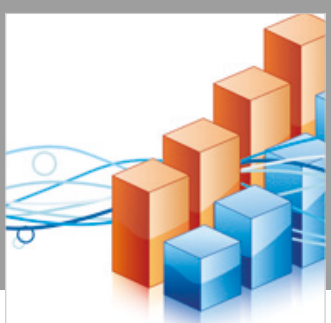

Advances in

Operations Research

\section{-n-m}
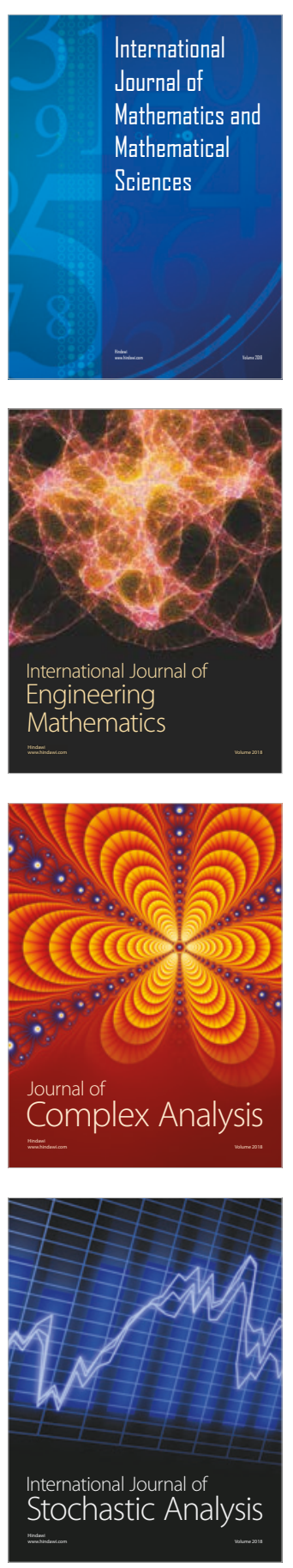
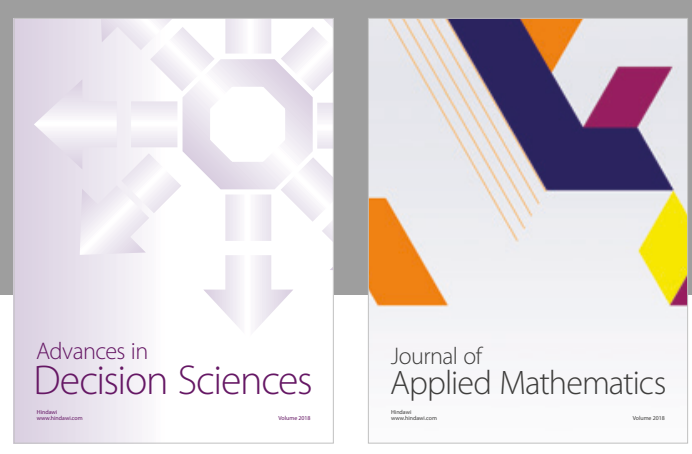

Journal of

Applied Mathematics
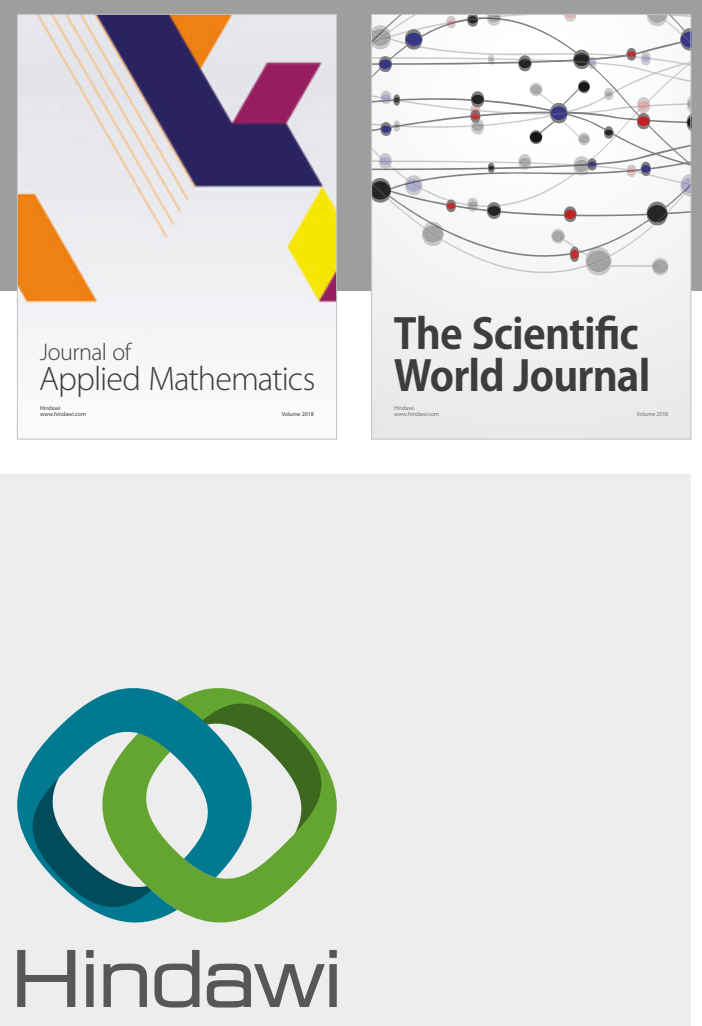

Submit your manuscripts at

www.hindawi.com

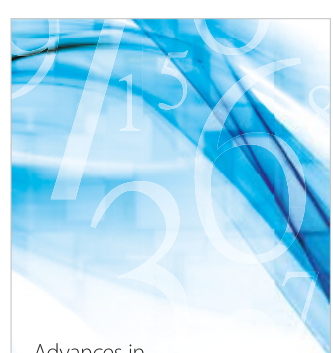

Advances in
Numerical Analysis
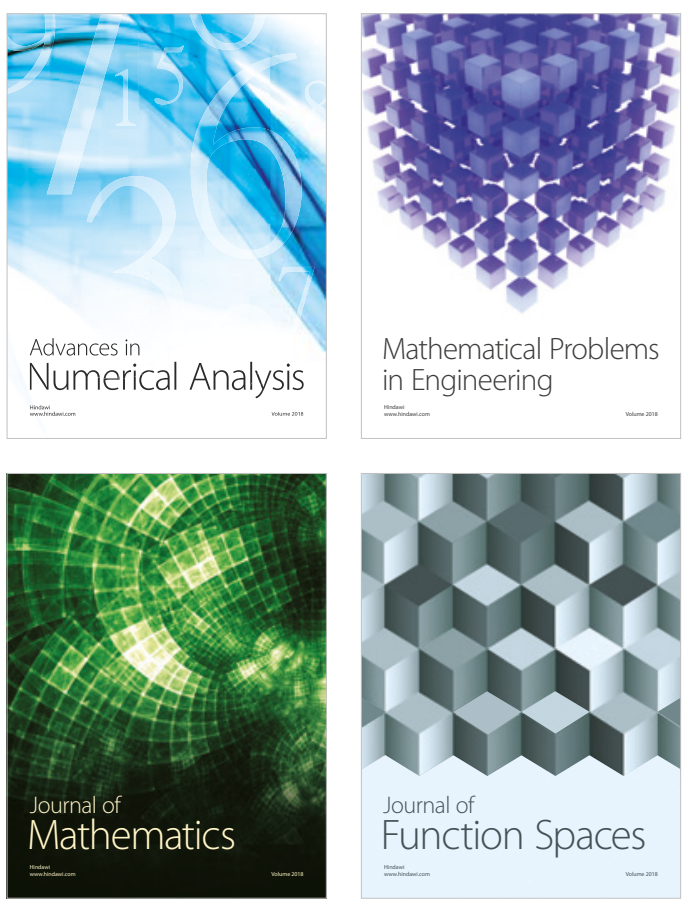

Mathematical Problems in Engineering

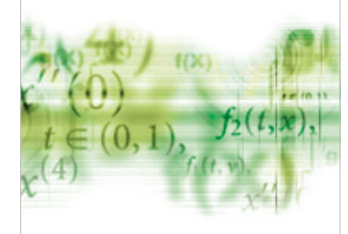

International Journal of

Differential Equations

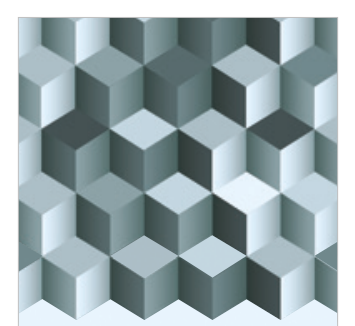

Journal of

Function Spaces
The Scientific

World Journal

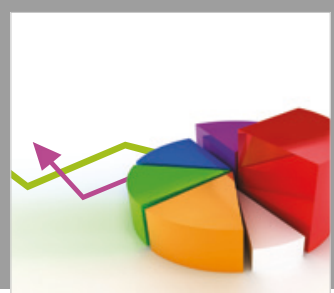

Journal of

Probability and Statistics
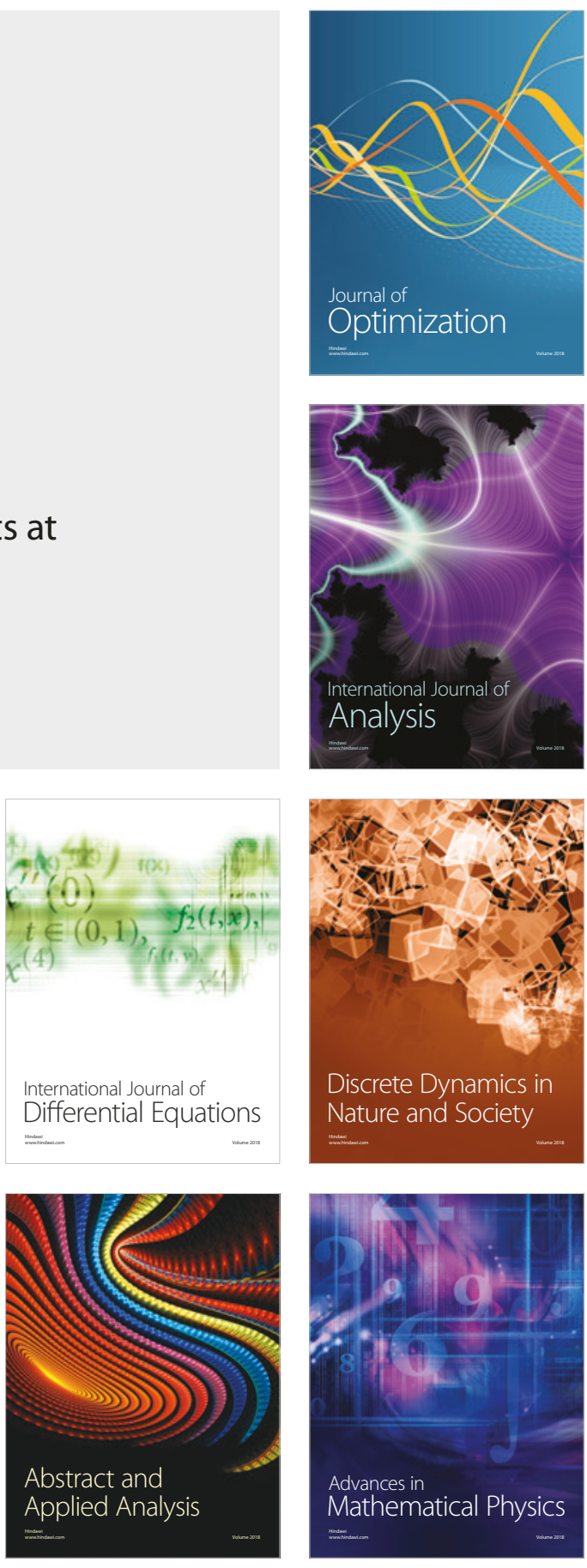